In this latter contingency, the possibility of an under-estimate of the potency of the vitamin $D_{3}$ concentrate is by no means negligible. The B.S.I. testwith or without minor modifications--has been carried out in these Laboratories for the past eight years, and I am indebted to my colleague, Dr. M. D. Wright, for the information that the accuracy rormally attained is indicated by fiducial limits at $p=0.99$ of approximately 75-133 per cent. It is, therefore, possible-especially in view of the strict legal requirements as to potency declarations associated with these oils-that the vendor of the 'synthetic' vitamin $D_{3}$ may have deliberately sold it on the basis of a very conservative estimate of potency. It is suggested therefore that before Stott and Harris's conclusions are generally accepted, much more detailed information should be provided by them on this and the other points raised.

Research Laboratories,

H. C. H. Graves.

Vitamins, Ltd.,

23 Upper Mall,

Hammersmith,

London, W.6.

${ }^{2}$ Nature, 155, 267 (1945).

British Pharmacopoeia, 597 (1932), and Addendum (1936).

\section{Pollen of Lime (Tilia spp.)}

PoLJen production in small-leaved lime (Tilia cordata Mill.), as the following figures show ${ }^{1}$, is comparable with that of durmast oak (Quercus petraea Liebl.) :

\begin{tabular}{|l|c|c|}
\hline \multicolumn{1}{|c|}{ Pollen output } & Tilia cordata & Quercus petra a \\
\hline Single flower & 43,500 & 41,200 \\
Ten-year-old branch system & $89 \times 10^{3}$ & $11.1 \times 10^{6}$ \\
Total for a pure stand $100 \times 100 \mathrm{~m}$ & $5,600 \times 10^{6}$ & $3,500 \times 10^{3}$ \\
50-year total for a similar stand & $280,490 \times 10^{8}$ & $34,410 \times 10^{6}$ \\
\hline
\end{tabular}

Oak is a typically anemophilous tree, and its pollen production in certain years at least is well known to be correspondingly high: the figures therefore need no comment. Two other groups of facts bespeak the importance of pollen production in Tilia :

(1) Lime pollen occurs in quantity in English and Welsh peat deposits covering a long period of postglacial time, and its presence in substantial proportion is held by Godwin ${ }^{2}$ to characterize the warmest phase of that period. Pollen analysis of a poat from the East Moors, Cardiff ${ }^{3}$, showed that at one horizon 56 per cent of the total tree pollen was lime.

(2) Lime pollen is present at certain times in considerable quantity in the atmosphere near lime trees and can be caught on adhesive surfaces exposed in the vicinity. Thus the following quantities of Tilia and other pollen (mainly grass) respectively were caught on $5 \mathrm{sq}$. cm. of a slide exposed horizontally on the roof of the National Museum of Wales, Cardiff (60 ft. above ground) on the dates stated ${ }^{4}$ : 1942 , June 29-July I (48 hours), Tilia 174, other pollen 834 ; July 1-2 (24 hours), 274 and 222 ; July 2-3, 49 and 306 ; 1943, June 30-July 1,34 and 97. Similar counts were obtained from slides exposed for us, by the courtesy of Prof. F. T. Brooks, on the roof of the Botany School, Cambridge, in 1943, namely, June 26-28, Tilia 173, other pollen 193; June 28-29, 36 and 60 ; June $29-30,66$ and 94.

So far from producing little pollen (as claimed by Yate Allen in the statement quoted by $\mathbf{M r}$.
Cartwright Farmiloe ${ }^{5}$ ) lime seems to be an outstanding example of a plant which, notwithstanding the fact that its flowers produce nectar and are regularly visited by insects in consequence, yet produces and sheds also an abundance of pollen.

National Museum of Wales, Cardiff.

H. A. HYDE

\section{Llandough Hospital, Cardiff.}

\section{A. Wmiliams.}

1 Erdtman, G., "An Introduction to Pollen Analysis" (Waltham, Mass., 1943).

2 New Phyt., 39 (1940).

Hyde, H. A.. Trans. Cardiff Nat. Soc, 69 (1936).

Hyde, H. A., and Williams, D. A. (unpublished).

${ }^{3}$ Nature, 155, 80 (1945).

\section{Naga, Naja, Naia or Naya?}

IN paragraph 19 of the review in Nature of October 21, 1944, of "The Fauna of British India", Colonel Wall states: "The generic name of the cobra should be altered to Naga. It was clearly the intention of Linnaeus to attach to it the name by which it is universally known to the natives of India--'nag' (pronounced narg). It is probable that this information was conveyed by letter and that he mistook the ' $\mathrm{g}$ ' for ' $\mathrm{j}$ '. Naja, and still less the Naia of some authors, have no meaning."

The two common Singhalese names for cobra are 'nāgayā' and 'naiā', or more correctly, 'nayā', and if, as Colonel Wall states, it is probable that Linnaeus's information was conveyed to him by letter and that he mistook a ' $g$ ' for a ' $j$ ', is it not equally probable either his correspondent considered ' $j$ ' and ' $i$ ' interchangeable, as has been customary, or that he actually wrote ' $y$ ', which Linnaeus mistook for ' $j$ ' ?

'Naja' has certainly no meaning to a Singhalese, but 'naiā' or 'nayä' will make him jump.

Coconut Research Scheme, W. V. D. PICRIS.

Lunuwila, Ceylon.

\section{P. J. Kipp}

THE description by the author of a recent communication ${ }^{1}$ of the apparatus for the continuous generation of gases at the ordinary laboratory temperature as a 'kip' is almost an insult to the work and memory of P. J. Kipp ${ }^{2}$. This eminent Dutch chemist was born more than a hundred years ago at Delft, where he founded the well-known firm of P. J. Kipp and Sons to which many chemists and physicists have been, and hope to be again, indebted for beautifully made scientific apparatus. A representation of Kipp's apparatus is incorporated in the seal of the Dutch Chemical Society.

We have become accustomed to the abbreviation of the name of the familiar burner as a 'Bunsen' and we may speak of Kipp's apparatus as a 'Kipp', but I, for one, hope it will never be described again as a 'kip'.

Chemistry Department,

C. S. Gibson.

Guy's Hospital Medical School,

(University of London), London, S.E.1.

1 Robertson, Nature, 155, 395 (1945)

${ }^{2}$ Chem. and Ind.. 5, 509 (1930). 